\title{
Effects of Isoproterenol, a Non-Selective $\beta$ - Agonist, on Lipid Metabolism of Rats : In Vitro and In Vivo Study
}

\section{Fotovati, Abbas}

Laboratory of Chemistry and Technology of Animal Products, Division of Applied Biological Chemistry, Graduate School of Bioscience and Biotechnology, Faculty of Agriculture, Kyushu University

Hayashi, Toshiya

Laboratory of Chemistry and Technology of Animal Products, Division of Applied Biological Chemistry, Department of Bioscience and Biotechnology, Faculty of Agriculture, Kyushu University

Tsuchida, Nobuyuki

Laboratory of Chemistry and Technology of Animal Products, Division of Applied Biological Chemistry, Graduate School of Bioscience and Biotechnology, Faculty of Agriculture, Kyushu University

\section{Ito, Tatsumi}

Laboratory of Chemistry and Technology of Animal Products, Division of Applied Biological Chemistry, Department of Bioscience and Biotechnology, Faculty of Agriculture, Kyushu University

https://doi.org/10.5109/24361

出版情報: 九州大学大学院農学研究院紀要. 45 (1)，pp.99-108，2000-11. Kyushu University バージョン：

権利関係 : 


\title{
Effects of Isoproterenol, a Non-Selective $\beta$-Agonist, on Lipid Metabolism of Rats: In Vitro and In Vivo Study
}

\author{
Abbas Fotovati*, Toshiya Hayashi, Nobuyuki Tsuchida* \\ and Tatsumi Ito** \\ Laboratory of Chemistry and Technology of Animal Products, Division of Applied Biological \\ Chemistry, Department of Bioscience and Biotechnology, Faculty of Agriculture, \\ Kyushu University, 6-10-1 Hakozaki, Higashi-Ward, Fukuoka 812-8581, Japan \\ (Received May 15, 2000 and accepted August 18, 2000)
}

\begin{abstract}
It is believed that $\beta$-adrenergic receptors are involved in fat metabolism through the induction of lipolysis. On the other hand, different dietary fats show different pattern of fat accumulation in animal body. In this study, first, in vitro lipolytic effect of isoproterenol in rat adipocyte has been studied, then its interaction with different dietary fats on fat accumulation in animal body (in vivo) has been studied. For in vitro study, adipocytes isolated from epidydimal fat were incubated with $10^{-5}$ to $10^{9} \mathrm{M}$ isoproterenol and freed glycerol content was measured as an index of lipolysis. For animal study, forty-eight male SD rats were divided into agonist-intaked and control groups and both of them were fed diets containing $12 \%$ of either beef tallow (BT), canola oil (CO), olive oil (OO) or safflower oil (SO) as fat source. After 4 weeks, the rats were killed and their abdominal fat mass and liver were dissected and weighed. The results of in vitro studies showed a potent lipolytic effect of isoproterenol on rat adipocytes. The $\mathrm{pD} 2$ values for isoproterenol was $7.345 \pm 0.018$. Amount of accumulated abdominal fat was not different between agoinst-intaked and control. It was concluded that, although isoproterenol had a potent lipolytic effect on rat adipocytes in vitro, its in vivo effect was not obvious, possibly due to less bioavailability of the agonist at adipocytes level in situ.
\end{abstract}

\section{INTRODUCTION}

There are several systems involved in energy metabolism of animal body. When the energy is needed in the body, systems such as lipolysis and glycolysis stimulate energy production through catabolic processes of energy stores, mainly of lipids and saccharides. Fats are one of the main energy stores of animal body. In lipolysis, fats, mainly triglycerides, were degraded into glycerol and fatty acids to produce a considerable amount of energy. There are some control systems regulating this process. Adrenergic system is considered as one of them. Two groups of adrenoceptors of this system, i.e., $\alpha$ and $\beta$ have almost opposite effects on fat metabolism, especially in white adipose tissue (WAT). The $\alpha$-adrenergic system especially $\alpha 2$-adrenoceptors show obvious anti-lipolytic activity and $\beta$-adrenergic receptors are generally considered as lipolysis-inducer of most animal species (Lafontan and Berlan, 1993). In the original classification of $\beta$-adrenergic receptors, there were only two types, i.e., $\beta 1$ and $\beta 2$-adrenoceptors (Lands et al., 1967).

* Laboratory of Chemistry and Technology of Animal Products, Division of Applied Biological Chemistry, Graduate School of Bioscience and Biotechnology, Faculty of Agriculture, Kyushu University, 6-10-1 Hakozaki, Higashi-Ward, Fukuoka 812-8581, Japan.

** Corresponding anthor (Email: tito@agr.kyushu-u.ac.jp) 


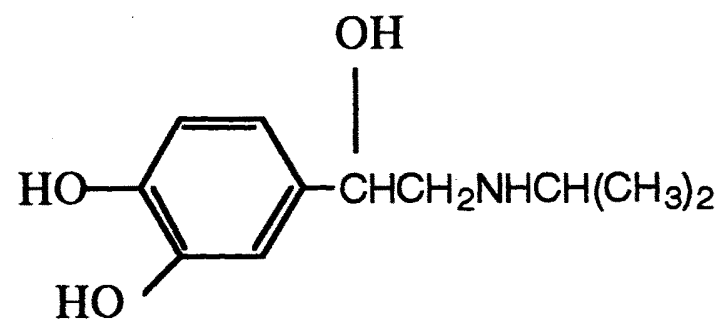

Fig. 1. Chemical structure of Isoproterenol

However, from early 80s, an "atypical" $\beta$-adrenoceptor (neither $\beta 1$ nor $\beta 2$ ), so-called $\beta 3$, was also found in rat adipocyte (Tan et al., 1983) and its gene was cloned in many other species (Emorine et al., 1989; Granneman et al., 1991 and Granneman et al., 1993). The patterns of distribution of different types of adrenoceptors and their functional significance in BAT and WAT are different among different species. The lipolytic activities of adrenergic system is achieved through adenylyl cyclase and resultant cAMP production in the adipocytes. cAMP acts as a "second messenger" and promotes the activation of CAMP-dependent protein kinase A which phosphorylates serine residues of hormone-sensitive lipase (HSL) and promotes its activation and its translocation towards lipid droplets (Egan et al., 1992).

Since a few decades ago, obesity has been considered as a major risk factor for some cardiovascular, metabolic and endocrine diseases. Therefore, many researchers have tried to manipulate fat metabolism for preventing excess fat accumulation in the body. Lipolysis was considered as one of the potential ways for removing the excess body fat. Additionally, there have been some studies indicating the possible interactions between dietary lipids and $\beta$-adrenergic lipolytic activities. It has been suggested that dietary lipids change the cell membrane composition and then affect adrenoceptor activity (For more details refer to Fotovati and Ito, 1998).

Our previous studies have shown some patterns of distribution and metabolism of intaked different dietary fats rich in either saturated fatty acids (SFAs), polyunsaturated fatty acids (PUFAs) and monounsaturated fatty acids (MUFAs) in the rat body. In the present study, effect of isoproterenol (Fig. 1), as a non-selective $\beta$-adrenoceptor agonist, in inducing lipolysis in rat adipocyte (in vitro) has been investigated. Then, an animal study investigating whether there are any interactions between the $\beta$-adrenergic activity and the type of intaked dietary fats or not has been performed.

\section{MATERIALS AND METHODS}

In Vitro study:

\section{Isolation of adipocytes:}

About $1 \mathrm{mg}$ of epididymal fat was dissected out from a 20 weeks old male SD rat and then adipocytes were isolated by collagenase digestion as previously described by Rodbell (1964). Briefly, adipose fragments were incubated for $60 \mathrm{~min}$ in $5 \mathrm{ml}$ Krebs-Ringer 
bicarbonate buffer containing albumin $(3.5 \mathrm{~g} / 100 \mathrm{ml})$ (KRBA), glucose $(6 \mathrm{mM})$ and collagenase IV $(3.5 \mathrm{mg} / \mathrm{ml})$ at $\mathrm{pH} 7.4$ and $37.5^{\circ} \mathrm{C}$ in a water bath under gentle shaking at 60-70 cycles/min. After digestion, adipocyte suspension was centrifuged at $3000 \mathrm{~g}$ for $5 \mathrm{~min}$ and the supernatant was filtered through a 150 mesh stainless steel filter. Adipocytes were washed three times with KRBA buffer to eliminate collagenase. After washing, 4 to 5 samples of the final cell suspension were counted in Neubauer's hematocytometer after being diluted with trypan blue stain.

\section{Lipolysis:}

For lipolysis study, isolated adipocytes $\left(1-1.5 \times 10^{4}\right.$ cells $)$ were incubated in polyethylene tubes with $1 \mathrm{ml} \mathrm{KRBA}(\mathrm{pH} 7.4)$ containing glucose $(6 \mathrm{mM})$ at $37^{\circ} \mathrm{C}$ with gentle shaking (60-70 cycles/min) in a water bath. Isoproterenol hydrochloride was added to the medium to reach the final concentration of agonist from $10^{-5} \mathrm{M}$ to $10^{-9} \mathrm{M}$. After $90 \mathrm{~min}$ of incubation, the reaction was stopped by placing the tubes in ice bath and $100 \mu l$ of aliquots of infranatant were taken for enzymatic determination of glycerol (glycerol kit, Boehringer Mannheim $\mathrm{GmBH}$ ) by using spectrophotometer (DU-62 Spectrophotometer, BECKMAN). Measured glycerol concentration was used as an index of lipolysis. Total lipid was evaluated gravimetrically after extraction with 5 vol. of chloroform-methanol (2 to $1 \mathrm{in} \mathrm{v/v)} \mathrm{mixture} \mathrm{(Folch} \mathrm{et} \mathrm{al.,} \mathrm{1957).} \mathrm{Different} \mathrm{concentrations} \mathrm{of} \mathrm{agonists} \mathrm{and} \mathrm{their}$ lipolytic effects were expressed as percentage compared to maximal isoproterenol effect and dose-response curve was made accordingly. Since lipolytic effect of both agonists reached a plateau at a given concentration, the concentration of isoproterenol that produced maximum effect was determined and used as a basic value. Then, a half-maximum effect on glycerol release, i.e., $\mathrm{EC}_{50}$ (as $\log \mathrm{mol} / \mathrm{l}$ ) and $\mathrm{pD} 2$-values (-log $\mathrm{EC}_{50}$ ) was determined in relation to isoproterenol maximal effect (Van Rossum, 1963).

\section{Animal Study:}

\section{Animals and diets:}

Forty-eight 7-weeks old male Sprague-Dawley rats (purchased from Seac Co. Ltd., Japan) initially weighing 250-290g were housed in individual stainless-steel wire-mesh cages with a free access to water and under a controlled condition, 12-h reverse light: dark cycle (08:00-20:00), $20^{\circ} \mathrm{C}$ in temperature and $60 \%$ relative humidity, in animal raising facility of Biotron Institute of Kyushu University. Commercial diet (Charles River $\mathrm{CRF}-1$ purchased from the same company) was used for adaptation. Four experimental diets were contained $12 \%$ of either beef tallow (BT), canola oil (CO), olive oil (OO) or safflower oil (SO) as lipid sources. Other ingredients were the same for all groups as indicated in Table 1. In beef tallow diet, $0.03 \%$ alpha-tocopherol (wt/wt) was added to the beef tallow itself before mixing with other ingredients, as an antioxidant.

\section{Experimental design:}

At first, all rats were raised on the commercial diet (Charles River CRF-1) for 7 days for adaptation. Then, they were assigned to two main agonist-intaked and control groups. Each group was further divided into four dietary sub-groups. Feeding diets contained $12 \%$ of either beef tallow, canola oil, olive oil or safflower oil as lipid sources. Rats were distributed by controlled randomization such that mean body weights were not 
Table 1. Composition of experimental diets ( $g / 100 g$ of diet)

\begin{tabular}{lcccc}
\hline \multicolumn{5}{c}{ Dietary sub-groups } \\
\hline Component & Beef tallow & Canola oil & Olive oil & Safflower oil \\
\hline Beef powder & 20 & 20 & 20 & 20 \\
Beef tallow & 12 & - & - & - \\
Canola oil & - & 12 & - & - \\
Olive oil & - & - & 12 & - \\
Safflower oil & - & - & - & 12 \\
AIN-76 Vitamin mix & 1 & 1 & 3.5 & 3.5 \\
AlN-76 Mineral mix & 3.5 & 3.5 & 0.3 & 0.3 \\
DL-Methionine & 0.3 & 0.3 & 0.2 & 0.2 \\
Choline bitartrate & 0.2 & 0.2 & 5 & 5 \\
Cellulose & 5 & 5 & 27.9 & 27.9 \\
Corn starch & 27.9 & 27.9 & 30 & 30 \\
Sucrose & 30 & 30 & 0.1 & 0.1 \\
Cholesterol & 0.1 & 0.1 & & \\
\hline
\end{tabular}

different among groups and dietary sub-groups. All groups were fed ad libitum. In agonist-intaked group, isoproterenol was dosed at $0.5 \mathrm{mg} / \mathrm{kg} \mathrm{BW} /$ day. Body weight and feed consumption were measured every other day and weight gain and feed intake were calculated. After six weeks, the rats after anesthetization by ether were killed by decapitation (carried out under the control of guidelines for Animal Experiment in Faculty of Agriculture and the Graduate Course, Kyushu University and the Law [No. 105] and Notification [No. 6] of the Government). Blood was collected and serum was obtained by centrifugation ( $1500 \mathrm{~g}$ for $15 \mathrm{~min}$ ) and stored at $-80^{\circ} \mathrm{C}$ until use. Abdominal adipose tissues (mainly peri-renal and mesenteric adipose tissues) and liver were excised, weighed and immediately frozen in liquid nitrogen and stored at $-35^{\circ} \mathrm{C}$ until analysis of fatty acid composition.

\section{Lipid extraction:}

Fat content of the diets and abdominal fat, liver, muscle and feces, was extracted by Folch's method (Folch et al., 1957). Briefly, about $0.6 \mathrm{~g}$ of tissue (1 $\mathrm{g}$ in the case of feces and $1 \mathrm{ml}$ for serum) were weighed and suspended in $5 \mathrm{vol}$. of chloroform-methanol mixture ( 2 to $1 \mathrm{in} \mathrm{v} / \mathrm{v}$ ). After homogenization, the suspension was filtered through a filter paper (Advantec $5 \mathrm{~B}, 125 \mathrm{~mm}$ ) and the solvent was evaporated by freeze-drying and fat content was quantified gravimetrically.

\section{Preparation of sample for determination of fatty acid composition by gas chromatography:}

Fatty acid composition of extracted lipid was analyzed by gas chromatography. For preparation of fatty acid sample, extracted lipid was hydrolyzed and methylated as previously described (Kawahara et al., 1997). Briefly, about $1 \mathrm{mg}$ of extracted fat was dissolved in $1 \mathrm{ml}$ of acetyl chloride and methanol dehydrate mixture (1 to $10 \mathrm{v} / \mathrm{v})$ and $100 \mu \mathrm{l}$ benzene and hydrolyzed by incubating in hot water bath $\left(80^{\circ} \mathrm{C}\right)$ for $120 \mathrm{~min}$. Fatty acids were extracted by hexane, and after dehydration, the solvent was evaporated by 
freeze-drying. Sample was dissolved in benzene as carrier, and injected to gas chromatograph (GC-14B, Gas Chromatograph, Shimadzu Co. Ltd.) equipped with a temperature programmable injector and capillary column [ $(30 \mathrm{~m}$ long with an internal diameter of $0.250 \mathrm{~mm}$ ), Ulborn]. Column temperature was programmed from 150 to $220^{\circ} \mathrm{C}$ at rate of $4^{\circ} \mathrm{C} / \mathrm{min}$. Detection was made with a FID detector.

\section{Chemicals:}

Krebs-Ringer's and BSA were purchased from Sigma Co. (St. Louis, MO., USA). Collagenase Type IV was provided from Worthington Biochemical Co. (USA). Glycerol kits were purchased from Boehringer Mannheim GmBH (Mannheim, Germany). Filter $5 \mathrm{~B}, 125 \mathrm{~mm}$ was obtained from Advantec (Japan). DL- $\alpha$-tocopherol was purchased from Nacalai Tesque (Japan). Isoproterenol hydrochloride was purchased from Sigma Co. Ltd.. DL-Methionine, cholesterol (cholesterin), sucrose and choline bitartrate were purchased from Nacalai Tesque. Cellulose was purchased from Advantec. All other organic and inorganic chemicals and reagents were of analytical grade and were purchased from Merck (Darmstadt, Germany), Sigma and Nacalai Tesque.

\section{Statistical analysis:}

Results are shown as means \pm SEM. The differences among groups were assessing by ANOVA and was followed by Fischer PLSD for assessing the difference between all pairs of control and isoproterenol-intaked rats. $P$-value less than 0.05 is considered as statistically significant. For statistical analysis, Power Pc Version of StatView software (Abacus Concepts Inc) was used.

\section{RESULTS}

\section{In vitro lipolytic study:}

Spontaneous glycerol release, i.e., basal lipolysis, was $0.322 \pm 0.031 \mu \mathrm{mol} / 100 \mathrm{mg} /$ $90 \mathrm{~min}$. Isoproterenol was full agonist and induced a dose--dependent lipolysis on isolated rat epididymal adipocytes (Fig. 2). Lipolytic effect of agonist, determined as concentration of released glycerol, reached a plateau at about $10^{-6} \mathrm{M}$. The mean half-maximum effect (pD2) values for isoproterenol was $7.345 \pm 0.018$.

\section{Animal study:}

In all of dietary sub-groups, there was no significant difference in daily feed intake and weight gain between control and agonist treated rats (Figs. 3a and b). However, among control groups, daily feed intake in BT (27.615 \pm 1.468$)$ was significantly higher than SO (25.062 \pm 2.163$)(P<0.05)$ (Fig. 3a). Weight gain was also significantly higher

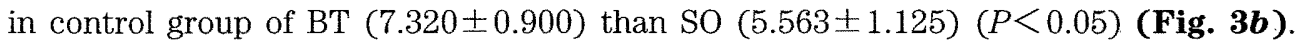
There was no significant difference in liver weight among the dietary groups and also between agonist-treated and control in each dietary group (Fig. $4 \boldsymbol{a}$ ). However, among control groups, liver weights in BT $(20.950 \pm 1.973)$ and CO $(19.862 \pm 3.040)$ were significantly higher than SO $(17.580 \pm 3.235)(P<0.05)$ (Fig. 4a). Amount of abdominal fat was not significantly different between agonist-intaked and control rats in all dietary groups (Fig. $4 \boldsymbol{b}$ ). 


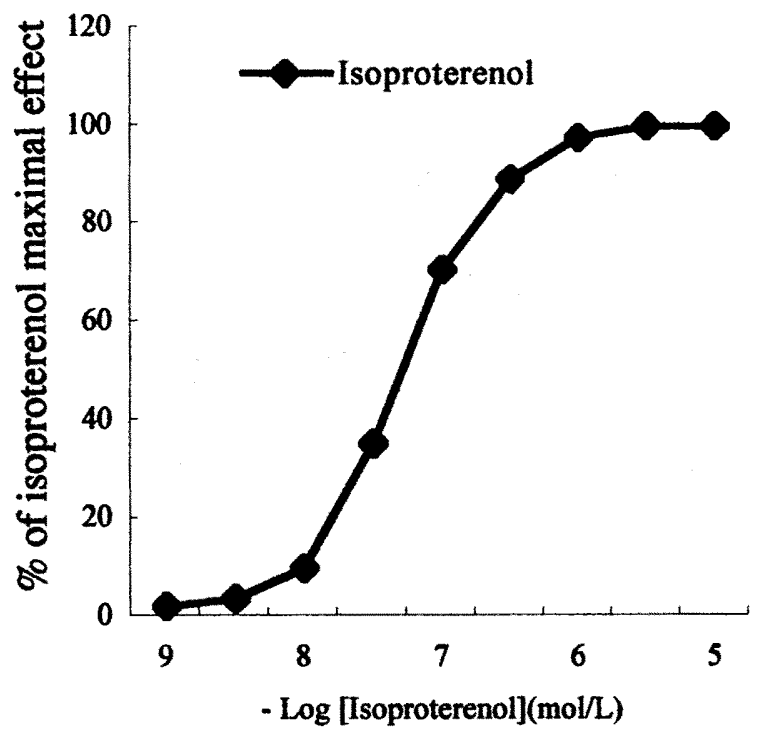

Fig. 2. Lipolysis induced by increasing the concentration of $(-)$ isoproterenol in rat epididymal adipocytes. The effects are expressed as \% relative to isoproterenol maximal effect. Values are means \pm SEM from 4-5 separate experiments.

Fatty acid composition of experimental diets is shown in Table 2. In every diet, MUFA was the most abundant fatty acid. BT contained a large amount of SFA, while CO and SO contained larger amount of PUFA. Fatty acids composition of abdominal fat, as a typical example, of control and isoproterenol-intaked rats of four dietary sub-groups is shown in Fig. 5. There was no significant difference in fatty acid composition between agonist-treated and control rats in every dietary Sub-group. The situation was similar in the case of liver, muscle and serum (Data not shown).

\section{DISCUSSION}

The results of this study showed in vitro lipolytic effect of isoproterenol and its failure to induce lipolysis in vivo in the rats fed different dietary fats.

In this study, isoproterenol showed a dose-dependent lipolytic activity in rat adipocytes (Fig. 2). This was in consistent with some previous studies (Hollenga et al., 1991; Umekawa et al., 1996; Carpéné et al., 1999; Fotovati et al., 2000). Isoproterenol is considered as a mixed non-selective $\beta$-agonist (Lafontan and Berlan, 1993), however, different concentration of it may play an important role in determining the type of $\beta$ -receptor to be stimulated. It has been shown that low concentration of catecholamine ( $10 \mathrm{nM}$ or lower) activates lipolysis through $\beta 1$-adrenoceptor activation, whereas the stimulation of $\beta 3$-adrenoceptor occurred at higher concentration (more than $1 \mu \mathrm{M}$ ). 
However, the main effect of isoproterenol on lipolysis was attributable to the activation of the atypical $\beta 3$-adrenoceptor, whereas the typical $\beta 1$-adrenoceptor play a small, subordinate role (Hollenga and Zaagsma, 1989). The results of our other study and results of other authors have shown that, although isoproterenol strongly stimulates lipolysis in rat adipocytes, its lipolytic effect is about 10 times weaker than selective $\beta 3$-agonists such as BRL 35135 (Fotovati et al., 2000; Hollenga et al., 1991; Umekawa et al., 1996). The order of the potency of lipolytic effect of isoproterenol compared to selective $\beta 1, \beta 2$ and $\beta$ 3 -agonists in rat was suggested as follows: $\beta 3$-agonists (CL316243 and BRL37344) $>$ isoproterenol as mixed agonist $>\beta 1$-agonist (dobutamine) $>2$-agonist (procaterol) (Atgie et al., 1997). Lipolytic activity of isoproterenol on other animal and human adipocytes has been studied in vitro (Milavec-Krizman and Wagner, 1978; Langin et al., 1991; Carpéné et al., 1999). Large species-specific differences exist in fat cell adrenoceptor distribution and in their relative importance in the control of the fat cell function. Although functional $\beta 3$-adrenoceptors coexist with $\beta 1$ - and $\beta 2$-adrenoceptors in a
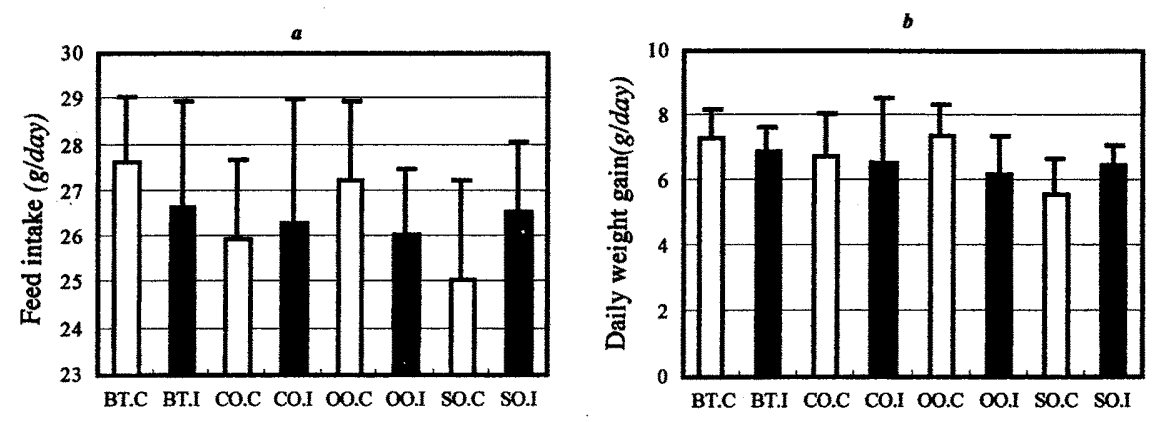

Fig. 3. Daily feed intake (a) and weight gain (b) in control (C) and isoproterenol-treated (I) rats. $\mathrm{BT}=\mathrm{Beef}$ tallow, $\mathrm{CO}=$ Canola oil, $\mathrm{OO}=\mathrm{Olive}$ oil, $\mathrm{SO}=$ Safflower oil. Values are means \pm SEM.
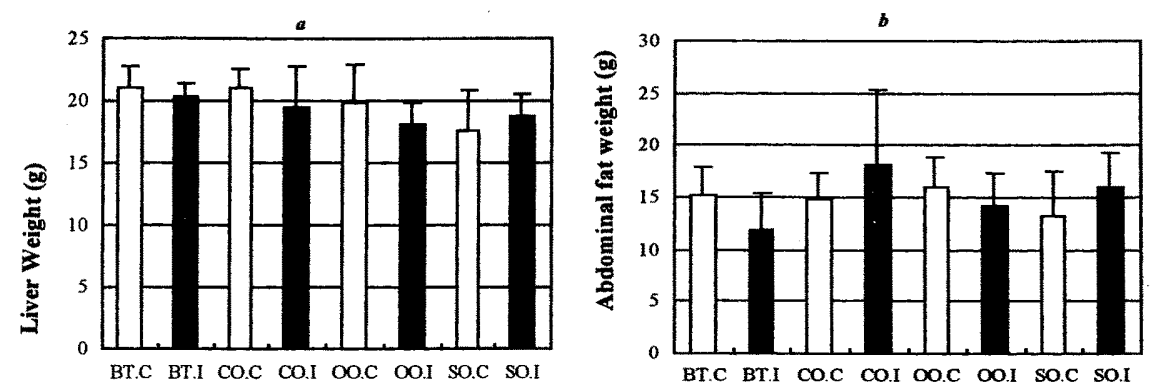

Fig. 4. Liver weight $(a)$ and abdominal fat weight $(b)$ in control $(C)$ and isoproterenol-treated (I) rats. $\mathrm{BT}=\mathrm{Beef}$ tallow, $\mathrm{CO}=$ Canola oil, $\mathrm{OO}=\mathrm{Olive}$ oil, $\mathrm{SO}=$ Safflower oil. Values are means \pm SEM. 
Table 2. Fatty acid composition of diets.

\begin{tabular}{ccrrrrrrrr}
\hline \multirow{2}{*}{ Diet } & \multicolumn{10}{c}{ Fatty acids } \\
\cline { 2 - 10 } & $14: 0$ & $16: 0$ & $16: 1$ & $18: 0$ & $18: 1$ & $18: 2$ & $18: 3$ & $20: 4$ & others \\
\hline Beef tallow & 2.13 & 26.5 & 4.45 & 10.04 & 48.52 & 1.79 & 0.11 & 0.26 & 6.2 \\
Canola oil & 0.0 & 9.51 & 1.21 & 4.42 & 52.53 & 17.86 & 8.59 & 1.14 & 4.74 \\
Olive oil & 0.5 & 15.2 & 1.72 & 2.63 & 68.73 & 6.95 & 0.84 & 1.06 & 2.37 \\
Safflower oil & 0.09 & 10.7 & 0.09 & 2.23 & 41.21 & 39.62 & 0.76 & 1.24 & 4.06 \\
\hline
\end{tabular}

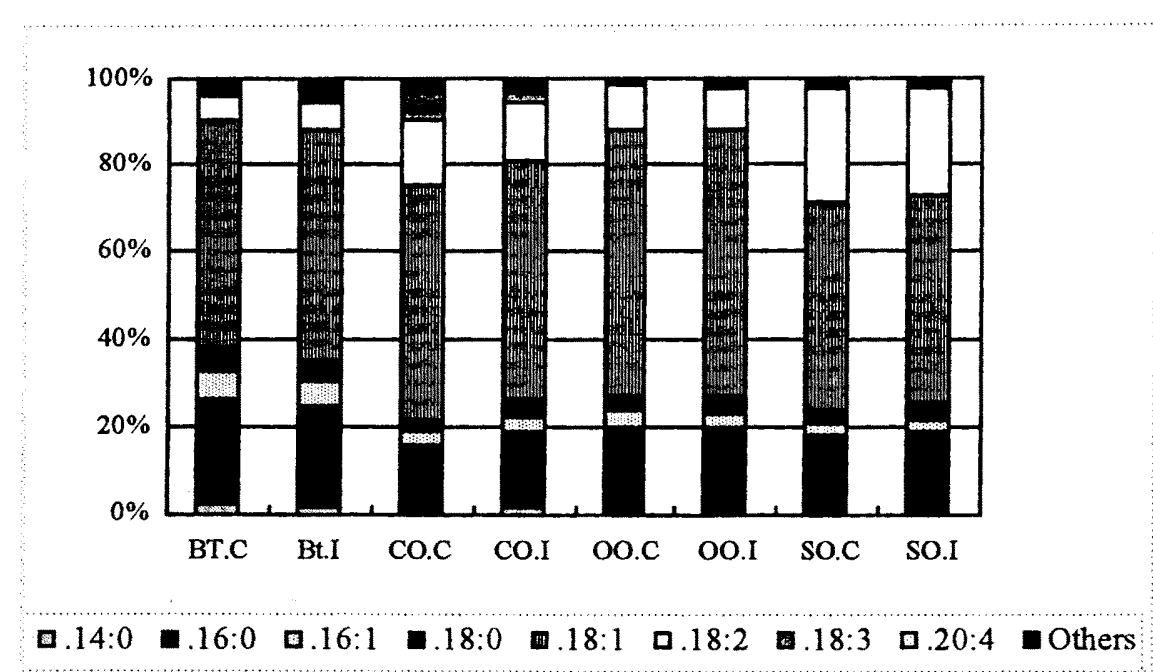

Fig. 5. Pattern of distribution of fatty acids in abdominal fat of control (C) and isoproterenoltreated (I) rats raised on different dietary fats. BT: Beef tallow, CO: Canola oil, OO: Olive oil, SO: Safflower oil.

number of fat cells; they are weakly active in guinea pig, primate, and human fat cells (Lafontan and Berlan, 1993).

In vivo lipolytic effects of isoproterenol has been shown in human and animals. It is believed that $\beta 1$ and $\beta 2$-adrenoceptors could play a role in triglyceride breakdown in vivo (Harms et al., 1982). Intravenous infusion of isoproterenol in fasted rabbits significantly elevated plasma non-esterified fatty acids, indicating increased lipolysis (Reverte and Rivascabanero, 1996). Injection of $0.05-0.15 \mathrm{mg} / \mathrm{kg}$ of isoproterenol to mice induced a dose-dependant, lipolysis (Shih et al., 1995). However, in the present animal study, inclusion of isoproterenol failed to show lipolytic activity in the rat body. There was no significant difference in the amount of abdominal fat between agonist-intaked and control rat in all dietary groups (Fig. $4 \boldsymbol{b}$ ). This might be due to weaker lipolytic activity of isoproterenol as a non-selective $\beta$-agonist, compared to selective $\beta 3$-agonists such as BRL35135. The other possibility is desensitization of $\beta$-adrenoceptors due to long term dosage of isoproterenol as indicated by the results of one study (Green et al., 1996). Low bio-availability of isoproterenol due to so-called "first-pass loss" by the liver is an 
another potential cause of failure of its activation in the present animal study (Pond and Tozer, 1984; Roland and Tozer, 1995). It is believed that large parts of isoproterenol will be eliminated by the liver during passing the gastrointestinal tract. Failure of lipolytic activity of isoproterenol was observed in all dietary groups. It was indicated that lipolytic activity of adrenoceptors might be reduced by feeding rats with SFA-rich diets such as beef tallow (Matsuo et al., 1997) and similar results have been observed in our other study using selective $\beta 3$-adrenoceptors (Fotovati et al., 2000). However, this phenomenon could not be observed in this study because of the basic failure of activation of the receptor by this agoinst.

Future studies by using alternative administration techniques, i.e., parenteral, which provides higher concentration of agonist at the adipocyte level may provide more information regarding non-selective adrenergic-induced lipolysis in rats fed different dietary fats. Such studies also provide more detailed information regarding the effect of diet itself on obesity and other fat-related metabolic disorders.

\section{CONCLUSION}

Although isoproterenol as one of the non-selective $\beta$-adrenergic agonist activated lipolysis in adipocytes in vitro, its lipolytic effect was not significant in animal body. This might be due to following reasons: 1) Non-selective agonist activities of isoproterenol, 2) lesser lipolytic activity of $\beta 1$-adrenoceptor, compared to $\beta 3$-adrenoceptor, 3 ) desensitization of $\beta$-adrenoceptors due to the long term dosage of isoproterenol and finally 4) lower concentration of the agonist bound to the adrenoceptors located on the surface of the adipocytes due to the reduction in the level of biologically available agonist after

first-pass loss in the liver. Results of the present study could not show any interaction between isoproterenol and the type of dietary lipids.

\section{ACKNOWLEDGEMENT}

This study was partly supported by a grant from Uehara Memorial Foundation .

\section{REFERENCES}

Atgie, C., F. D. Allaire, and L. J. Bukowiecki, 1997 Role of $\beta 1-$ and 3-adrenoceptors in the regulation of lipolysis and thermogenesis in rat brown adipocytes. Am. J. Physiol., 273(4): C1136-C1142

Carpéné, C., J. Galitzky, E. Fontana, C. Atgié, M. Lafontan, and M. Berlan, 1999 Selective activation of $\beta 3$-adrenoceptors by octopamine:comparative studies in mammalian fat cells. Naunyn Schmiedeberg's Arch Pharmacol., 359: 310-321

Egan, J. J., A. S. Greenberg, M-K. Chang, S. A. Wek, J. M. C. Moos and C. Londos, 1992 Mechanism of hormone-stimulated lipolysis in adipocytes: Translocation of hormone-sensitive lipase to the lipid storage droplet. Proc. Natl. Acad. Sci. USA, 89: 8537-8541

Emorine, L. J., S. Marullo, M. M. Briend-Sutren, G. Patey, K. Tate, C. Dalavier-Klutchko and A. D. Strosberg, 1989 Molecular characterization of the human beta 3-adrenergic receptor. Science, 245: $1118-1121$

Folch, J., M. Lees, and G. M. Sloane-Stanley, 1957 A simple method for isolation and purification of total lipids from animal tissues. J. Biol. Chem., 226: 497-509

Fotovati, A. and T. Ito, 1998 Distribution and metabolism of dietary lipids in animal body. Rec. Res. Devel. in Nutrition Res., 2: 69-90 
Fotovati A., T. Hayashi, and T. Ito, 2000 Lipolytic effect of BRL 35 135, a $\beta 3$-agonist, and its interaction with dietary lipids on the accumulation of fats in rat body. J. Nutr. Biochem. (in press)

Garcia-Sainz, J. A., and J. N. Fain, 1980 Effect of adrenergic amines on phosphatidyl-inositol labelling and glycogen synthase activity in fat cells from euthyroid and hypothyroid rats. Mol. Pharmacol., 18 $116-121$

Granneman, J. G., K. N. Lahners and A. Chaudury, 1991 Molecular-cloning and expression of rat beta 3-adrenergic receptor. Mol. Pharmacol., 40: 895-899

Granneman, J. G., K. N. Lahners and A. Chaudhry, 1993 Characterization of the human beta 3-adrenergic receptor gene. Mol. Pharmacol., 44: 264-270

Green, A., R. M. Carroli and S. B. Dobias, 1996 Desensitization of $\beta$ adrenergic receptors in adipocytes causes increased insulin sensitivity of glucose transport. Am. J. Physiol., (Endocerinol. Metab.34) 271: E271-E276

Harms, H. H., J. De Vente and J. Zaagsma, 1982 Beta-adrenoceptor blocking agents and lipolysis. Br. J. Clin. Pharmacol., 13: 181-186

Hollenga, C., and J. Zaagsma, 1989 Direct evidence for the atypical nature of functional $\beta$ -adrenoceptors in rat adipocytes. Br. J. Pharmacol., 98: 1420-1424

Hollenga, C., F. Brouwer and J. Zaagsma, 1991 Relationship between lipolysis and cyclic AMP generation mediated by atypical $\beta$-adrenoceptors in rat adipocytes. $\mathrm{Br}$. J. Pharmacol., 102: 577-580

Kawahara, S., K. Inoue, T. Hayashi, Y. Masuda and T. Ito, 1997 Lipids easy to accumulate in the liver and lipids hard to accumulate in it. Nutrition Res., 17: 1013-1023

Lafontan, M., and M. Berlan, 1993 Fat cell adrenergic receptors and the control of white and brown fat cell function. J. Lipid Res., 34: 1057-1091

Lands, A. M., A. A. Arnold, J. P. McAuliff, F. P. Luduena and T. G. Brown, 1967 Differentiation of receptor systems activated by sympathomimetic amines. Nature, 214: $597-598$

Langin, D., M. P. Porttillo, J-S. Saulnier-Blache and M. Lafontan, 1991 Coexistence of three $\beta$ -adrenoceptor subtypes in white fat cells of various mammalian species. Eur. J. Pharmacol., 199: 291-301

Lipworth, B. J. 1996 Clinical pharmacology of $\beta 3$-adrenoceptors. Br. J. Clin. Pharmacol., 42: 291-300

Matsuo, T. and M. Suzuki, 1997 Brain $\beta$-adrenergic receptor binding in rats with obesity induced by a beef tallow diet. Metabolism, $\mathbf{4 6}$ : $18-22$

Milavec-Krizman, $\mathrm{M}$, and $\mathrm{H}$. Wagner, 1978 Effects of the adrenergic agonists isoprenaline and noradrenaline and the alpha-blocking agents dihydroergotamine and phentolamine on the lipolysis in isolated fat cells of the rat, guinea pig, dog and man. Biochem. Pharmacol., 27: 2305-2310

Pond, S. M. and T. N. Tozer, 1984 First-pass elimination: Basis concepts and clinical consequences. Clin. Pharmacokinet., 9: $1-25$

Reverte, M. and L. Rivas-Cabanero, 1996 Effects of the $\beta 3$-adrenoceptor agonist BRL 37344 on lipomobilization and plasma glucose levels in conscious fasted rabbits. Can. J. Physiol. Pharmacol., 74: $251-256$

Rodbell, M. 1964 Metabolism of isolated fat cells. I. Effects of hormones on glucose metabolism and lipolysis. J. Biol. Chem., 239: 375-380

Rowland, M. and T. N. Tozer, 1995 Hepatic Extraction. In "Clinical pharmacokinetics: Concepts and application", ed. by M. Rowland and T. N. Tozer, Williams \& Wilkins, Baltimore, pp. 125-126

Shih, M. F., and P. V. Taberner, 1995 Selective activation of brown adipocyte hormone-sensitive lipase and cAMP production in the mouse by $\beta 3$-adrenoceptor agonists. Biochemical Pharmacol., 50: $601-608$

Tajima, A., S. Kawahara, K. Shin, K. Imaizumi, T. Nakamura and T. Ito, 1995 Is beef tallow really hazardous to health?. Nutrition Res., 15: 1429-1436

Umekawa, T., T. Yoshida, N. Sakane, and M. Kondo, 1996 Effect of CL 316243, a highly specific $\beta 3-$ adrenoceptor agonist, on lipolysis of human and rat adipocytes. Horm. Metab. Res., 28: 394-396

Van Rossum, J. M. 1963 Cumulative dose-response curves. II. Technique for the making of dose-response curves in isolated organs and the evaluation of drug parameters. Arch. Int. Pharmacodyn., 143: $299-333$ 